\title{
PROJEÇÃO E SOFRIMENTO PSÍQUICO NA PARANOIA
}

Luiz Carlos Tarelho*

\begin{abstract}
RESUMO. O presente artigo se propõe a discutir o sofrimento psíquico e o papel exercido pela projeção na paranoia. Ele questiona a relação estabelecida por Freud entre paranoia e homossexualidade e traz à tona a questão dos enclaves psicóticos ligados a mensagens parentais, que assumem a forma de injunções paradoxais e não se prestam a uma retomada ativa e simbolizante por parte da criança. Enclaves que tendem a se enquistar no plano do superego, impedindo a evolução deste para o nível edipiano e produzindo um curto-circuito na estruturação da tópica psíquica, uma vez que parte deste superego passa a ocupar um espaço intermediário entre o eu e o mundo externo e a propiciar um tipo de projeção diferente do descrito por Freud, que é próprio do universo psicótico e do grau de certeza que acompanha as produções delirantes subjacentes.
\end{abstract}

Palavras-chave: Projeção; paranoia; superego.

\section{PROJECTION AND PSYCHIC SUFFERING IN PARANOIA}

\begin{abstract}
The aim of this paper is to discuss psychological suffering and the role of projection in paranoid states. It criticizes the relationship established by Freud between paranoid states and homosexuality, and brings about the question of psychotic enclaves linked to parental messages that manifest themselves as paradoxes and do not allow the child to actively symbolize these contents. These enclaves tend to install themselves at the level of the superego, preventing the superego from evolving to the Oedipian level. This produces a short circuit in the psychological topic structure, as the superego occupies an intermediary space between the ego and the external world, and the result is the coming into existence of projection in different terms than those described by Freud. Those projections can be thought of as something specific to the psychotic universe and relate to the degree of certainty that accompanies delusions lived by the individual in that state.
\end{abstract}

Key words: Projection; paranoid states; superego.

\section{PROYECCIÓN Y SUFRIMIENTO PSÍQUICO EN LA PARANOIA}

RESUMEN. Este artículo propone discutir el sufrimiento psíquico y la función ejercida por la proyección en la paranoia. Se cuestiona la relación establecida por Freud entre paranoia y homosexualidad y plantea la cuestión de los enclaves psicóticos asociados a mensajes parentales, que asumen la forma de imposiciones paradójicas y no se prestan a una retomada activa y simbolizante por parte del niño. Enclaves que tienden a enquistarse en el plano del superyó, impidiendo su evolución para el nivel edipiano y produciendo un cortocircuito en la estructuración de la tópica psíquica una vez que una parte de este superyó pasa a ocupar un espacio intermedio entre el yo y el mundo externo y a proporcionar un tipo de proyección diferente de lo descripto por Freud, que es proprio del universo psicótico y del grado de seguridad que acompaña las producciones delirantes subyacentes.

Palabras-clave: Proyección; paranoia; superyó.

\footnotetext{
Doutor em Psicanálise pela Université Dénis-Diderot (Paris-França), pós-doutor pela FCM-UNICAMP e professor do Curso de Psicologia da Universidade Bandeirante de São Paulo.
} 
O objetivo do presente trabalho é discutir a questão do sofrimento psíquico na paranoia sob a ótica do mecanismo da projeção. A conjunção desses três termos não constitui novidade nenhuma tendo em vista que, de um lado, a paranoia sempre foi, desde o início, na história da psicanálise, ligada à projeção e, de outro lado, que esta última, como todo mecanismo de defesa, está ligada a um sofrimento psíquico. Se tomarmos isso como um pressuposto, somos de imediato confrontados com a questão de saber o sentido de retomarmos aqui esta discussão nos termos propostos. Duas razões podem ser alegadas para justificar essa empreitada. A primeira é que a ligação íntima estabelecida por Freud entre a paranoia e a projeção não deixou de gerar dúvidas, inclusive dentro do próprio pensamento freudiano, levando a um questionamento sobre as diferenças entre este processo na neurose e na psicose, e que culminou na famosa tese lacaniana do retorno no plano do Real do que foi foracluído no plano do Simbólico. Se tomarmos a proposta lacaniana não como a última palavra sobre o assunto, mas como contribuição importante que permitiu retomar e repensar em outros termos, esta polêmica questão, que permanece ainda em boa medida aberta, podemos dizer, então, que um empreendimento neste sentido é mais do que justificável. A segunda, que é decorrência da primeira, tem a ver com a relação entre esse mecanismo específico e o sofrimento psíquico em questão. Aqui também a hipótese clássica freudiana - de que o sofrimento psíquico na paranoia tem a ver com uma libido homossexual inaceitável - tem sido objeto de questionamentos, principalmente pelo fato dela se inscrever na lógica muito mais do conflito (e, portanto, da neurose) do que das falhas básicas que caracterizam as psicoses. Esta necessidade de outro paradigma para se poder ter acesso ao universo psicótico já começa a se tornar mais evidente a partir do texto freudiano sobre o narcisismo, que aponta para um possível deslocamento da questão da angústia para o âmbito da fragilidade/integridade do Eu. Assim, abre-se uma nova perspectiva sobre a relação entre o sofrimento psíquico na paranoia e o mecanismo que se encontra na determinação dos sintomas. É dentro desta nova perspectiva, que busca repensar a origem desse sofrimento juntamente com o mecanismo de defesa a ele associado, que se situa o presente trabalho.

\section{PARANOIA E PROJEÇÃO}

Ao retomarmos os passos de Freud nesse intento, verificamos que seus primeiros textos se situam ainda no marco da sua neurótica, isto é, a da dita teoria da sedução. No primeiro texto, "Rascunho H", o autor afirma que "o propósito da paranoia é rechaçar uma idéia que é incompatível com o ego, projetando seu conteúdo no mundo externo" (Freud, 1895/1969a, p. 256). Ele recorre a um exemplo que alude a uma cena de sedução, cuja lembrança produzia excitação sexual e acionava uma censura (contra a ideia de ser uma mulher depravada). E é esta censura que Freud julga ser incompatível com o Eu necessitando assim ser transposta para fora, via projeção, passando a ser percebida como uma recriminação vinda de fora: "as pessoas estavam dizendo aquilo que, de outro modo, ela diria a si mesma" (p. 255). Daí a autorreferência da paranoia, que serve, segundo ele, justamente para provar a pertinência da projeção.

O mesmo esquema é retomado no "Rascunho K" (Freud, 1896/1969b, p. 275) e também nos "Novos comentários sobre as psiconeuroses de defesa", em que ele reafirma a idéea de que a projeção é o elemento fundamental na paranoia e está ligado à recusa da crença na autocensura: "na paranóia a autoacusação é reprimida por um processo descrito como projeção. É reprimida pelo estabelecimento do sintoma defensivo de desconfiar das outras pessoas" (Freud, 1896/1969c, p. 182, grifos do autor).

Embora a tendência nesses primeiros textos, como se pode verificar também na Carta 22 de sua correspondência com Jung (MacGuirre, 1976), seja a de pensar a projeção como estando envolvida com um distúrbio essencialmente perceptivo, do qual a projeção constitui o grande pivô, dois detalhes merecem ser destacados, pois podem dar lugar a outros desdobramentos. O primeiro é a relação que Freud estabelece entre a projeção na paranoia e o que, nesse momento, constitui um resquício do que será o Superego. Isso está presente na ideia da autoacusação, da autocensura, que é o elemento rechaçado. $O$ segundo tem a ver com a explicação do porquê o elemento projetado aparece como uma realidade. A alusão mais interessante sobre isso aparece na Carta 22 enviada a Jung, onde ele afirma que este elemento assume o caráter de uma percepção na medida em que o investimento libidinal é removido ao ser transposto para a extremidade perceptiva (MacGuirre, 1976).

O passo seguinte dado por Freud - que é também o principal - no sentido de consolidar sua tese ligando a paranoia e a projeção é, sem dúvida, seu trabalho sobre as "Memórias do Presidente Schreber" (Freud, 1911/1993a). Se Freud deve a Jung a sugestão da leitura das "Memórias", podemos dizer também que seu texto sobre Schreber é, em grande medida, endereçado a este cobiçado interlocutor e, com ele, à classe médica psiquiátrica, que permaneciam ainda reticentes em relação à tese sobre a primazia da sexualidade. Com esse trabalho, Freud teve a oportunidade de mostrar que esta primazia se aplicava 
também ao campo das psicoses. E ele faz isso colocando no centro do palco, como se sabe, a questão da homossexualidade inconsciente. Aqui não é mais a autocensura que se torna intolerável, mas sim o desejo homossexual. Percebe-se aí o deslocamento em relação ao elemento sobre o qual incidia a projeção nos primeiros textos: passa-se de algo que era do registro da censura para algo que é do registro direto da sexualidade.

Sabemos o quanto este passo foi importante para defender a primazia do sexual, mas não podemos deixar de assinalar também o quanto o registro do superego (da lei), que é central na paranoia, acabou sendo esvaziado. De outro lado, é preciso lembrar que, da mesma forma que esta reflexão permitiu à Freud consolidar sua tese sobre a projeção na paranoia, ela também foi decisiva em relação ao questionamento sobre o modelo de projeção utilizado. Embora ele chegue a perceber essa inadequação, sua explicação continua baseada num modelo centrado num distúrbio perceptivo, assim como sua explicação da paranoia permanece tributária de um modelo neurótico, calcado no mecanismo do recalque (Tarelho, 1999a). Nesse contexto de incertezas, ele chega inclusive a fornecer dois modelos diferentes desse mecanismo. No primeiro, o amor homossexual é inicialmente transformado em ódio, sendo este o sentimento projetado. No segundo modelo, é o próprio sentimento de amor que é projetado, pois a mudança de sinal (amor em ódio) aparece no processo de transposição para fora, como uma deformação para impedir que a projeção seja reconhecida (Freud, 1911/1993a).

Estas diferentes versões, além de revelarem uma dúvida em relação à natureza do afeto sobre o qual atua a projeção, mostram ainda o quanto Freud parecia insatisfeito com suas elaborações sobre isso, fato que ele fez questão de deixar registrado nesse trabalho em duas ocasiões. O primeiro registro encontra-se logo na sequência da descrição desse mecanismo:

Seriamos tentados a tomar este impressionante processo como sendo o que há de mais significativo na paranoia e como absolutamente patognomônico da mesma, se não fôssemos lembrados a tempo que: 1) a projeção não desempenha o mesmo papel em todas as formas de paranoia, e 2) que ela não ocorre somente na paranoia, mas também em outras circunstâncias da vida anímica; e que se lhe pode, além disso, atribuir uma participação regular em nossa postura diante do mundo exterior. Se não procuramos em nós mesmos as causas de certas sensações de origem sensorial, como procuramos as de outras sensações, mas se, ao contrário, as situamos no exterior, esse processo normal também merece o nome de projeção. Tendo sido alertados que, para se compreender a projeção, esbarramos em problemas psicológicos mais gerais, nos decidimos a reservar para um outro contexto o estudo da projeção... (Freud, 1911/1993a, p.289, tradução nossa).

O segundo registro encontra-se no final do seu texto e constitui a passagem que Lacan (1966) contribuiu para tornar célebre, em que Freud diz o seguinte:

\begin{abstract}
Foi incorreto dizer que a sensação interiormente reprimida é projetada para o exterior; antes nos damos conta de que o que foi interiormente suprimido retorna do exterior. A investigação aprofundada do processo da projeção, que postergamos para outra oportunidade, nos trará a certeza definitiva sobre esse assunto. (Freud, 1911/1993a, p.294, tradução nossa).
\end{abstract}

Se Freud não voltou a tratar do assunto de forma sistemática, Lacan (1966), por sua vez, tomou esta última passagem freudiana como ponto de partida de sua reflexão sobre a psicose. Essa ideia de que algo foi suprimido na paranoia encontra-se presente na sua tese sobre a Foraclusão do Nome do Pai. Da mesma forma, a ideia de que é justamente o que foi suprimido internamente o que retorna do exterior encontrou plena expressão na sua explicação do delírio como manifestação do Real. Assim, a expressão freudiana "o que foi interiormente suprimido retorna do exterior" (Freud, 1911/1993a, p. 294) pode ser reescrita na famosa fórmula lacaniana, segundo a qual o que foi foracluído do Simbólico reaparece no Real (Lacan, 1966).

Com essa reflexão, Lacan contribuiu para mostrar que esse processo na psicose não pode ser entendido a partir do modelo clássico da projeção, dita psicológica, que acaba reduzindo o delírio a um simples efeito de deformação do processo de percepção. Sua reflexão foi decisiva também para mostrar que o que Freud denomina de supressão tem a ver com uma falha grave no plano do processo de simbolização, segundo ele pela falta de um Significante estruturador, batizado de Nome do Pai. E, além disso, por meio da controvertida noção de Real, acabou abrindo uma nova via de reflexão para se pensar o delírio como estando ligado a um terceiro nível de realidade que, em nosso entendimento, tem a ver com uma forma do desejo e, portanto, da sexualidade que subsiste sem mediação alguma.

Este terceiro nível de realidade constitui, segundo nosso ponto de vista, baseado nas reflexões laplancheanas (conforme, por exemplo, Laplanche, 1999), o âmbito da sexualidade inconsciente por excelência e do qual Freud parece ter tido uma boa 
intuição em algumas passagens a propósito do delírio e da projeção, as quais valem a pena ser retomadas aqui. $\mathrm{O}$ primeiro texto em que se pode encontrar uma alusão à questão desse terceiro nível de realidade, "Psicopatologia da vida cotidiana" (Freud, 1901/1969d), é dedicado a estender as descobertas da psicanálise para outras esferas da vida psíquica, mas que acaba tocando na questão da psicose e, por esta via, na da projeção. Ele toma como exemplo a paranoia para corroborar sua tese sobre a existência de um conhecimento inconsciente. Segundo Freud, é justamente com base nesse conhecimento que o paranoico encontra uma via para a projeção de seus conteúdos inconscientes. É por isso também que o paranoico se apega a pequenos detalhes, que, em geral, passam desapercebidos para as outras pessoas, e acaba conferindo significado a quase tudo, pois, em função desse saber inconsciente, tudo passa a ser interpretável. Mas Freud vai além ao dizer que a convicção do paranoico, nesse sentido, não deixa de ser justificada, isto é, está baseada num dado verdadeiro, mas que é da ordem de outro nível de realidade, que é inconsciente: "Em certo sentido, portanto, o paranoico tem razão, pois reconhece algo que escapa à pessoa normal, vê com clareza maior do que alguém de capacidade intelectual normal" (Freud, 1901/1969d, p.251). O delírio é assim visto como uma crença que, embora deforme a percepção, repousa sobre algo verdadeiro, mas que pertence a outro tipo de realidade.

Uma linha de raciocínio muito parecida é defendida em "Delírios e sonhos na Gradiva de Jensen" (Freud, 1907/1969e), em que a fé inabalável do delírio deriva de um conhecimento inconsciente sobre um dado de realidade de natureza sexual, que não pode ser admitido no âmbito da realidade psíquica e que acaba aparecendo como vindo de fora (realidade material). Como diz Freud, "existe uma parcela de verdade oculta em todo delírio, um elemento digno de fé que é a origem da convicção do paciente, a qual, portanto, até certo ponto, é justificada" (Freud, 1907/1969e, p. 74).

Essa discussão foi retomada e ampliada em 1921 no texto "Sobre alguns mecanismos neuróticos no ciúme, na paranoia e na homossexualidade". Neste texto, Freud (1921/1993b) dá outro passo importante, que é admitir a existência de um modo de comunicação próprio a este nível de realidade inconsciente, quando relata que há relação entre o inconsciente do paranoico e o inconsciente das pessoas sobre as quais incidem suas projeções.

Ora, temos o sentimento de descrever de modo muito insatisfatório tanto o comportamento do paranoico, quanto o do ciumento e o do perseguido, dizendo que eles projetam para o exterior, nos outros, o que eles não querem perceber em seu próprio interior. É verdade que é o que eles fazem, mas eles não projetam, por assim dizer, no vazio, em que não há nada de semelhante; ao contrário, eles se deixam guiar pelo conhecimento que têm do inconsciente e transferem sobre $\mathrm{o}$ inconsciente dos outros a atenção que eles retiram de seu próprio inconsciente. (Freud, 1921/1993b, p. 91, tradução nossa).

Este texto destaca, pois, o papel do inconsciente alheio no deslocamento realizado pela projeção colocando a ênfase na similitude dos conteúdos, o que serviria como base sobre a qual se opera a transferência da atenção que o paranoico realiza de seu inconsciente para o inconsciente do outro. Embora fundamentais para se ampliar a compreensão do que se convencionou denominar de projeção, estas indicações de Freud permaneceram como pontilhados sem que ele tenha retomado o assunto para aprofundar a discussão. Nessa mesma direção, merece também destaque um texto de 1937, onde ele escreve que o delírio encontra apoio para sua força de convicção no núcleo de realidade histórico-vivencial (historisch), que ele acaba contribuindo para resgatar na tentativa de encontrar um sentido para um fragmento biográfico ligado a vivências infantis que permaneceram excluídas do mundo simbólico do sujeito (Freud, 1937/1989c).

\section{PROJEÇÃO E SOFRIMENTO PSÍQUICO NA PARANOIA}

A história de constituição do inconsciente é inseparável da história de constituição do eu e também da história do sofrimento psíquico do sujeito. Como vimos, de acordo com a hipótese canônica freudiana, o sofrimento psíquico na paranoia tem a ver com a questão da homossexualidade, tese defendida no seu principal texto sobre o assunto (Schreber) e jamais revista por ele. Mas, como já foi também apontado, depois de seu texto sobre o narcisismo, ficou claro que, apesar da questão da homossexualidade não estar ausente, o ponto central em torno do qual gira o sofrimento psíquico nesses casos tem a ver com a própria constituição do eu e sua integridade, cuja precariedade o torna excessivamente dependente do outro e da alteridade que o ameaça o tempo todo. E coisa que a literatura psicanalítica não cessa de mostrar - esta ameaça é bem diferente daquela que se encontra por trás dos conflitos psíquicos que estão na base das neuroses. Enquanto os conflitos se situam muito mais no plano das frustrações e das privações, a falta de integridade nas psicoses tem a ver com a 
intromissão incontornável dos pais, que gera falhas graves no processo de constituição do psiquismo e coloca o eu numa posição de eterna fragilidade. Em outras palavras, trata-se, no mais das vezes, de uma ameaça de morte, que é, antes de tudo, a morte psíquica, a perda da integridade do eu, que não consegue fazer frente à alteridade instalada em seu seio.

Para caracterizar melhor este sofrimento é preciso, portanto, entender como se deu, e isso em cada caso, a própria constituição do eu, com as relações de dependência que ele vive, com o tipo de alteridade que ele enfrenta e com as ameaças que tudo isso representa. Evidentemente, quando se fala em teoria, pensa-se na possibilidade de se representar isso num modelo, para o qual encontramos suporte na teoria da sedução generalizada. Trabalhamos com a hipótese, segundo a qual esta falha no processo de constituição do psiquismo do paranoico, de que se deve a uma relação transferencial originária, marcada por mensagens parentais que não puderam ser objeto de uma retomada ativa por parte do sujeito, a criança, dentro do processo de tradução e simbolização onde se situa a constituição do eu e do recalcado (este como resto do que não foi metabolizado). Mais especificamente, sustentamos a ideia, segundo a qual estas mensagens parentais concernem desejos que se manifestam na forma de injunções paradoxais e que são candidatos a permanecer como um enclave psicótico no psiquismo da criança. Um enclave que, por seu parentesco com os imperativos categóricos do superego, possui a tendência a se enquistar nessa instância, o que inclusive ajuda a explicar melhor não apenas a ferocidade do superego na paranoia, que constitui a base do delírio de perseguição, como também o quanto estes sujeitos permanecem presos a um superego arcaico (Tarelho, 1999a, 1999b).

Essa hipótese permite pensar que, além do perigo proveniente do recalcado, comum ao quadro normalneurótico, o paranoico está exposto também a outro perigo, que vem do superego e que é muito mais desestruturante, pois constitui uma ameaça à integridade do eu, situada numa instância que lhe parece familiar, mas que o coloca numa posição de completa passividade, deixando-o sem recursos, tanto simbólicos quanto energéticos, para lidar com a violência paralisante que constituem essas injunções paradoxais enquistadas nesta instância. Essa ameaça pode ser melhor entendida se levarmos em conta que a lógica do paradoxo, que sustenta essas injunções, constitui um ataque sobretudo à lógica da racionalidade que serve de guia ao eu em seu trabalho de simbolização e de produção de sentido. Ela coloca o eu diante de dilemas insolúveis concernindo sua própria origem e integridade. Segundo Racamier
(1991), os sujeitos submetidos a essas organizações paradoxais, geralmente, experimentam o sofrimento de não terem sido psiquicamente engendrados.

Com o auxílio de um exemplo baseado numa vinheta clínica, propomos mostrar aqui como essas injunções paradoxais, enquistadas no superego, acabam interferindo no desenvolvimento não apenas do eu, mas também do próprio superego e na possibilidade de integração dessas duas instâncias.

Trata-se de uma jovem mulher acometida por um quadro paranoide e que organiza sua vida em torno de uma ideia delirante, segundo a qual seu namorado vive tentando difamá-la moralmente (tendo como foco a questão da traição amorosa), apesar de amá-la bastante, o que a faz ter a impressão de que lida com dois homens, um amoroso e acolhedor, e outro completamente oposto, isto é, perseguidor e controlador. A relação com este namorado é marcada por um vínculo altamente ambivalente e dependente, revelando espelhismos dos vínculos originários, principalmente com a mãe, com quem teve uma ligação de natureza simbiótica. Portadora de um quadro depressivo e esposa de um homem descrito como distante e meio agressivo, esta mãe parece tê-la tomado como um objeto parcial para tentar remendar esse buraco narcísico e acabou colocando obstáculos no caminho que a conduzia ao pai como objeto edipiano. Não que ela não tenha percorrido este caminho, mas foi ao preço de inscrever a culpa no seio de seu ser e no âmbito da lógica do paradoxo, pois seu desejo nasce da injunção paradoxal materna, que proíbe o acesso ao pai e que pode ser resumida mais ou menos assim: "Tu podes desejar (este pai), desde que eu seja o objeto deste desejo!". Em outras palavras: "Para todos os efeitos, tu não podes desejar!" (este é o termo latente da injunção paradoxal). Injunção que remetia a outra, que pode ser formulada mais ou menos assim: "Se percorreres esse caminho que te levas ao pai, tu deixas de existir para mim!'. E, como se trata de uma injunção paradoxal, ela vai acompanhada da contrapartida latente: "Se ficares presa apenas a mim, da mesma forma, deixas de existir, pois te tornas sujeito sem desejo, isto é, mero objeto do meu desejo!"'. Em síntese, trata-se de uma injunção bem diferente da interdição clássica, em que o pai é interditado porque pertence à mãe e cuja sentença poderia ser expressa nos seguintes termos: "Tu não podes desejar este pai porque eu o amo!". No caso em questão, ele se encontra interditado porque a filha pertence à mãe. Assim, estamos diante de uma injunção que proíbe, pura e simplesmente, o sujeito de desejar: "Tu não podes desejar este pai porque tu és minha!".

Essas injunções parecem ter interferido drasticamente na estruturação da constelação edipiana 
e nas consequências produzidas sobre o desenvolvimento do eu, do superego e da dinâmica que se estabeleceu entre estas instâncias. O pai não foi propriamente excluído como objeto de desejo, mas esse desejo ficou marcado por um paradoxo: ao invés de se transformar a posteriori em objeto de interdição, como seria a regra, ele parece ter sido criado pela interdição. Temos aí a força do arbitrário atravessando o espaço edipiano. No plano presente, ela busca um substituto deste objeto paterno, mas ele só existe como objeto de interdição, logo, como uma espécie de extensão do objeto mãe. Por isso, nas suas relações amorosas, não há espaço para a ambiguidade, pois rapidamente se ascende a luz da inadequação. Tudo precisa ser previamente esclarecido e acordado.

No plano do desenvolvimento do eu, verifica-se a disputa entre duas tendências opostas, sendo que a passividade predomina. Ele não sucumbiu totalmente ao desejo materno nos moldes da sideração, como se verifica na esquizofrenia, mas também não conseguiu se libertar de sua influência. Não que tenham faltado tentativas de se rebelar. Sua história parece marcada por esse movimento desde a infância, em que o significante da rebeldia se inscreveu e forneceu a base para um movimento que organizou o eu da vida adulta. Mas esse movimento não podia deixar de ser acompanhado pelo sentimento de culpa e de inadequação, que impediu a concretização do corte. E, na luta entre essas duas forças, acabou predominando o poder do desejo materno. Apesar de ter conseguido obter um diploma de nível superior e conquistado uma invejável formação cultural e humanista, não se sente apta para nada e não consegue encontrar uma atividade que lhe permita se realizar profissionalmente e financeiramente, continuando ainda dependente, inclusive economicamente. Seu eu vive um conflito insolúvel entre, de um lado, a necessidade de autonomia e, de outro, a necessidade de aprovação do outro, que tem a ver com seu superego.

No caso desta instância, chama atenção o nível de rigidez, de controle do eu e, ao mesmo tempo, de incapacidade de exercer seu papel referencial de representante da lei. Trata-se de um superego que parece não tolerar nenhum grau de ambiguidade, de ambivalência e muito menos de transgressão; que não é capaz de fazer acordos e nem de fazer exceções; que vive à espreita de um deslize do eu para poder condená-lo e martirizá-lo; e, o que é mais intrigante, foge da raia quando o eu precisa de seu aval, seja para legitimar uma decisão ou mesmo para avaliar a adequação de uma ideia ou comportamento, sobretudo se o outro se encontra concernido. Nesses casos, a demanda do eu dirigida ao superego é, invariavelmente, remetida ao outro. Assim, nunca consegue se autorizar e assumir seus desejos porque nem o eu e nem o superego consegue fornecer esse aval, reforçando a dependência em relação ao outro, que precisa sempre ser consultado. E, diante do primeiro sinal de desaprovação do outro, mesmo que seja remota, dispara internamente o alarme da censura, dando origem a um ciclo persecutório, que começa com o sentimento de culpa e termina com a punição vinda do outro (no caso do namorado, essa punição assume, em geral, a forma de uma difamação, mas que inclui também a ideia de um complô visando sua eliminação). Seu eu vive assim numa posição de extrema dependência desse superego, o qual, por sua vez, parece incapaz de assumir seu papel e de dar respaldo ao eu, pois quase sempre que é acionado pelo eu acaba remetendo à demanda para fora, para o outro. Outro que, em função do lugar ameaçador que ocupa desde a origem, não tem como se livrar da pele do perseguidor, ainda mais se ele, na relação transferencial, contribui - como é o caso do namorado - para aguçar esse embate entre o ego e o superego. Assim, para contrabalancear a dúvida que marca o eu quanto a seus direitos e capacidades, insurge-se uma certeza que tem a ver com a hostilidade e a injustiça do outro.

\section{SUPEREGO E PROJEÇÃO NA PARANOIA}

Com o auxílio deste material clínico, acreditamos poder sustentar que a solução para os impasses apontados acima, em relação à questão da projeção na paranoia, passa pela reconsideração do papel exercido pelo superego nesse processo. Como vimos, em suas primeiras incursões sobre o tema, Freud parece caminhar nessa direção ao afirmar que o elemento central na paranoia está ligado à recusa da crença na autocensura (Freud, 1896/1969b). Nesse momento de sua obra, a desconfiança que o paranoico desenvolve em relação às outras pessoas tem a ver com a autocrítica que se torna intolerável. Em 1914, no célebre texto sobre o narcisismo, Freud (1914/1969f) avança abertamente nessa direção tomando o delírio de observação como uma espécie de prova da existência do ideal do ego, revelando inclusive sua gênese:

\footnotetext{
O reconhecimento desse agente nos permite compreender os denominados 'delírios de sermos notados' ou, mais corretamente, de sermos vigiados, que constituem sintomas tão marcantes nas doenças paranoides. (...) Um poder dessa espécie, que vigia, que descobre e que critica todas as nossas intenções, existe realmente. (...) Os delírios de estar sendo vigiado apresentam esse poder numa forma regressiva, revelando assim sua gênese e a
} 
razão por que o paciente fica revoltado contra ele, pois o que induziu o indivíduo a formar um ideal do ego, em nome do qual sua consciência atua como vigia, surgiu da influência crítica de seus pais (transmitida por intermédio da voz)... (Freud, 1914/1969f, p. 102, grifo do autor).

As consequências dessa nova intelecção para a compreensão do assim denominado mecanismo da projeção na paranoia parecem tão importantes quanto evidentes, mas, apesar disso, não encontramos na reflexão posterior de Freud nenhuma aproximação nesse sentido. Nas duas outras grandes oportunidades que ele retomou a questão das psicoses (como é o caso do texto "Neurose e Psicose"), o mesmo restringiu-se a afirmar a esse respeito que o papel do superego deveria ser levado em conta em toda forma de enfermidade psíquica (Freud, 1924/1969g).

Nossa hipótese se apoia justamente na necessidade de se levar melhor em conta o papel do superego e isso na esteira das ideias sustentadas acima, que apontam nessa mesma direção. Entretanto, essas mesmas ideias indicam também a necessidade de se dar um passo a mais em relação a essas pistas deixadas por Freud, postulando que a constituição do superego na paranoia é marcada por uma lógica diferente, própria do universo psicótico. No quadro teórico no qual se inscreve nossa reflexão, um autor que também sustenta esta tese é Dominique Scarfone (1994). Para ele, enquanto o superego em geral é constituído por uma moral mais ou menos flexível, o superego do psicótico é marcado por uma moral inexorável, em que a interdição dos pais assume caráter implacável e a presença invasora deles no psiquismo da criança parece algo incontornável. Em suas palavras, o superego na psicose "seria inteiramente preenchido (plein); seria o que existe de mais 'forte' no eu psicótico; seria sempre o estrangeiro, mas não o que falta; seria o objeto sem buraco, sem falha, impedindo qualquer tipo de aproximação. Tão presente, tão familiar no centro do eu psicótico, que tudo o resto se torna estrangeiro" (Scarfone, 1994, p. 105, tradução nossa).

Embora Scarfone se refira à psicose de modo geral, acreditamos que essa tese se aplique mais propriamente aos quadros da paranoia e da melancolia. $\mathrm{E}$, de acordo com nossa hipótese, a lógica que governa esse universo psicótico da paranoia é a das injunções paradoxais, marcado por uma estrutura de pensamento fechada e absolutista, em que predomina a desqualificação e o império do arbitrário. Uma lógica que, como vimos, acaba levando as injunções parentais à formação de enclaves psicóticos dentro do superego da criança. Enclaves que vão, por sua vez, interferir no desenvolvimento do superego e na estruturação de toda a tópica psíquica. Apoiados no material clínico apresentado acima, podemos avançar a hipótese segundo a qual esses enclaves acabam impedindo a evolução normal do superego para o nível edipiano, que se organiza em torno das interdições parentais e que são acompanhadas das respectivas identificações e idealizações próprias desse cenário, dando lugar ao desenvolvimento de uma instância que é capaz de funcionar de forma mais ou menos integrada ao ego apesar de se colocar como representante interna da lei.

Encontramos também apoio para sustentar essa hipótese no trabalho de Didier Anzieu (1975) sobre a transferência paradoxal, em que ele afirma que esta lógica, além de perturbar gravemente a constituição do narcisismo e do eu, interfere também no desenvolvimento do superego. Em suas palavras, nesta conjuntura, "o superego não pode evoluir até o nível edipiano e ambivalencial; ele permanece confundido com o ideal do ego e o investimento pulsional que ele recebe tem a ver essencialmente com a pulsão de morte." (Anzieu, 1975, p. 65-66, tradução nossa).

\section{A POSIÇÃO DE EXTERIORIDADE DO SUPEREGO NA PARANOIA}

$\mathrm{Da}$ intelecção que tivemos do material clínico apresentado, parece-nos possível avançar a hipótese de que, nesses casos, em função dos enclaves formados pelas injunções paradoxais, o superego - ou pelo menos parte dele - não encontra inserção no espaço da tópica psíquica, mantendo seu parentesco muito vivo com os objetos externos. Essa hipótese permite, em nosso entendimento, dar um salto na compreensão do mecanismo da projeção na paranoia e no sofrimento psíquico subjacente.

De acordo com a compreensão que se desprende do que Freud avançou em seu texto sobre o narcisismo a respeito do delírio de observação, poder-se-ia dizer que é a retirada da libido narcísica do material internalizado (portanto, de natureza homossexual) o que faz com que este último retorne ao seu lugar de exterioridade e assuma, assim, um caráter persecutório. Esta hipótese, apesar de pertinente, nos parece mais adequada para se explicar a projeção no contexto da vida psíquica normal-neurótica, em que este material pode se encontrar de fato investido narcisicamente. Mas, no âmbito da psicose, é difícil imaginar que as injunções paradoxais possam se tornar objeto de tal investimento. Ao contrário, elas estão muito mais próximas da pulsão de morte, como acabamos, aliás, de ver nas postulações de Anzieu (1975). Além disso, o próprio Freud, no contexto da segunda tópica, sem, entretanto, fazer o elo com a 
psicose, estabeleceu uma sólida relação entre a projeção e a pulsão de morte, chegando inclusive a ligar a origem desse mecanismo à necessidade de expulsar as ameaças decorrentes desta força pulsional destrutiva (Freud, 1920/1989a e 1924/1989b). Esta tendência pulsional destrutiva, que ameaça a própria tópica e que por isso mesmo precisa ser deslocada para fora, tende a se manifestar de formas derivadas, como é o caso do ódio.

Em nosso entendimento, esses enclaves psicóticos no superego constituem um verdadeiro perigo de morte para o psiquismo, pois colocam em risco a tópica na medida em que representam uma heteronomia radical no plano dessa estrutura, ameaçando o tempo todo a integridade do eu, e também na medida em que impedem o fechamento da tópica já que parte do superego fica excluída, presa ao outro de alguma maneira. Essa é a marca dos quadros paranoides: a de uma ameaça contínua, que coloca em risco a própria sobrevivência do eu e que certamente tem a ver com essa dificuldade de fechamento da tópica. No caso citado, esta ameaça se manifesta principalmente de duas formas. Primeiro, por uma difamação, que coloca em risco constante a integridade do eu e que, no fundo, constitui uma representação atenuada de um perigo maior envolvendo a própria vida, pois esta ameaça esconde outra, à qual se encontra associada, revelando um complô que tem como alvo a sua aniquilação. Segundo, por um controle, que envolve, sobretudo, a esfera do desejo e que só faz reforçar a posição de passividade e de dependência do eu em relação ao outro. Em ambos os casos, tratam-se de ameaças que vêm de fora, do outro, e que, além de serem acompanhadas por uma certeza, revelam um trabalho de deslocamento.

Dentro da perspectiva aberta pela reflexão aqui desenvolvida, esse deslocamento, juntamente com a certeza à qual ele dá lugar, pode ser entendido a partir da posição que ocupa o superego dentro dessa tópica de cunho paranoide. Nossa hipótese é que, nesses casos, o superego - ou pelo menos parte dele - em função dos enclaves que abriga e da heteronomia radical que representa, não consegue manter o seu lugar de inserção na tópica psíquica, ficando a meio caminho entre o outro e o eu, entre o externo e o interno, o fora e o dentro. Ele fica, assim, ocupando um lugar ambíguo, indevido, um espaço de transição. Um espaço que parece ter algo a ver com o que Winnicott (1975) denominou de espaço transicional, que constitui uma área intermediária entre o eu e o outro e que é a base sobre a qual se assenta a possibilidade da fantasia, do jogo, da criação, da confiança, do desejo, enfim, da separação entre a realidade psíquica (mundo interno) e a realidade material (mundo externo) e de uma percepção que consiga levar em conta minimamente esta distinção. E, como já foi apontado por outros autores, entre as grandes faltas que marcam os quadros psicóticos, o espaço transicional ocupa um lugar central. Merece destaque nesse sentido uma formulação de Maurice Dayan (1985):

Delirar no real, independentemente do receptáculo escolhido para isso, supõe que entre o dentro e o fora não exista 'espaço de transição', onde possa se manifestar o jogo e a ilusão, mas sim um afrontamento e um 'corpo a corpo cerrado' - isso quando não são muito mais o caso de 'englobamentos recíprocos que beiram ao infinito'. Desse modo, os psicóticos 'abertamente' e os esquizofrênicos, de modo crônico, são destituídos da 'terceira área' que Winnicott descreveu como interposta entre uma 'realidade psíquica interior ou pessoal' e o mundo onde vive e morre o sujeito. Para eles, o interno e o externo não estão separados por esta área de experiência potencial, onde se conjugam e se distinguem, ao mesmo tempo, o indivíduo e o meio ambiente no qual o primeiro deposita confiança (segundo os termos de Winnicott); pelo contrário, o dentro e o fora estão colados um ao outro por frente e por trás. Daí que os esquizofrênicos não se iludem e também não se permitem a latitude da crença: 'eles não têm senão vertigens e convicções; e, por um singular paradoxo, eles acabam por mergulhar na fantasia e no erro'. (Dayan, 1985, p. 243-244, grifo do autor, tradução nossa).

Nosso objetivo aqui não é apenas chamar a atenção para essa falta, que parece estrutural na psicose, mas propor um passo a mais com a afirmação da hipótese segundo a qual estas duas coisas estão interligadas, ou seja, que a ausência desse espaço transicional na paranoia se deve justamente ao fato do superego ocupar este espaço, substituindo-o de algum modo. Pode-se imaginar que, quanto maior for esta invasão do superego, maior será também o prejuízo causado a este espaço e ao que ele representa. Chegamos a esta conclusão a partir da análise de casos semelhantes ao descrito neste trabalho, no qual o superego, por conta dessas injunções paradoxais, não consegue encontrar o seu lugar de ancoragem dentro da tópica psíquica (que é estabelecida pelo ego), ficando colado à superfície do ego e numa posição onde este último se liga ao mundo externo, isto é, num espaço de transição, em que deveria se instaurar um distanciamento que impede justamente a confusão entre o mundo interno e o mundo externo e que corresponde ao espaço transicional, descrito por 
Winnicott (1975), o qual, como vimos, não cumpre sua função na psicose. Sendo assim, parece pertinente supor que estamos tratando de fenômenos interrelacionados, senão do mesmo fenômeno. Mas acreditamos que a grande justificativa para sustentar esta hipótese vem do potencial explicativo que ela possui, pois ela lança uma nova luz sobre a questão da projeção na paranoia e da estruturação do delírio.

Se esta hipótese é justificada, podemos dizer que, pelo menos na paranoia, não se trata de uma mera ausência do denominado espaço intermediário, da terceira área, com também o designou Winnicott (1975), mas muito mais de uma usurpação desse espaço pelo superego, que vê assim não apenas uma compensação para o espaço perdido por ele na tópica, senão também uma oportunidade de potencializar o seu poder, já que, por essa via, ele acaba ganhando peso e ares de realidade (material, externa). Daí a certeza do paranoico: as ameaças e as perseguições que ele denuncia, com tanta convicção e força, de fato não constituem meras representações deslocadas para fora da sua realidade psicológica interna, mas antes significantes pertencentes a outro nível de realidade, ao qual os enclaves psicóticos do superego estão ligados e que, nestes casos, se situam neste espaço de transição entre o mundo interno e o mundo externo. Esses enclaves, assim como a sexualidade inconsciente, pertencem a um terceiro nível de realidade, que é o da vida pulsional, o qual, normalmente, se situa de modo transversal à realidade psicológica (vivência subjetiva interna) e à realidade material (externa), habitando estes dois níveis e funcionando, de certa maneira, como um elo entre eles. Ocorre que, no caso desses enclaves psicóticos, este terceiro nível de realidade, ao invés de permanecer na condição de parasita dos outros dois níveis, situando-se de modo transversal a estes, acaba assumindo certa independência, já que não pode ser submetido a nenhum processo de traduçãometabolização, e passa, então, a se situar de modo paralelo. E, como ele ocupa uma posição intermediária entre o externo e o interno, pode assumir o peso de realidade material, passando não apenas a competir com esta última, mas até a assumir certa primazia sobre ela.

Desse modo, pode-se concluir que o deslocamento operado pela projeção na paranoia é diferente do operado pela projeção na vida psíquica normalneurótica. Enquanto este último se apoia na posição transversal da realidade pusional-inconsciente para colocar para fora elementos da vida psíquica que geram conflitos, o primeiro se apoia na posição de exterioridade (em relação à tópica) que assumiram os enclaves psicóticos do superego para tentar segregar de vez esses enclaves que ameaçam a tópica psíquica, cortando todo e qualquer vínculo com eles. $\mathrm{O}$ problema é que, como eles estão alojados no superego e este se encontra ainda colado ao ego assim como a criança se encontrava colada à mãe, esse deslocamento tem o mesmo sentido que o corte que não pode ser feito na infância, isto é, representa uma ameaça de desestruturação, de morte. Em outras palavras, isso implica em radicalizar a relação mortífera existente entre o ego e o superego. Esse é, na verdade, o grande drama do paranoico: quanto mais ele tenta se livrar da alteridade presente nesta instância, cuja ameaça é onipresente, mais aumenta a fragilidade do eu e mais persecutório se torna o mundo, pois este superego, em função do lugar intermediário que ocupa, tende a tomar partido do outro que habita este mundo e que acaba se tornando o receptáculo da projeção. Outro que não somente não se reconhece no quadro hostil e persecutório pintado pelo paranoico, como acaba reagindo contra transferencialmente a este deslocamento e à própria hostilidade com que é tratado já que ele se torna também objeto de ódio, o que, por sua vez, só faz reforçar o sofrimento psíquico e a certeza do sujeito quanto ao seu delírio.

No exemplo clínico citado, esse esquema revelase claramente nas ameaças descritas, que vão desde a sensação de ser vigiada e controlada, passando pela difamação e chegando até o complô visando sua morte. Podemos dizer que estas ideias são justificadas por, pelo menos, quatro razões. Primeiro, porque, como Freud (1921/1993b) já havia assinalado, seu inconsciente se deixa guiar pelo conhecimento que tem do inconsciente do outro, no qual esse desejo de controle parece estar presente em alguma medida. Segundo, porque subsiste outro excessivamente concreto dentro de seu superego arcaico, que não conseguiu evoluir para um nível de abstração mais próximo do modelo edipiano. Terceiro, porque este seu superego encontra-se numa posição, ao mesmo tempo, de relativa exterioridade em relação à tópica psíquica e de grande proximidade com o superego do outro, ao qual se remete o tempo todo, revelando uma falha no nível da fronteira externa da tópica psíquica. $\mathrm{E}$, por fim, porque este superego encontra-se colado diretamente ao ego, sem nenhum espaço de mediação, e exerce sobre este último um controle total pela sua onipresença e onipotência.

Seria preciso se levar em conta também a dimensão defensiva desta percepção, na medida em que ela se inscreve numa tentativa de afastar esta ameaça, uma tentativa que, além disso, contribui para circunscrevê-la a um lugar conhecido já que ela procede de um lugar não identificado, situado nesse espaço intermediário, e de onde deveria brotar exatamente o contrário: não o controle e a censura, mas a inspiração e a confiança. Nesse contexto, fazer 
com que a ameaça provenha do outro (ou de fora, isto é, da realidade externa) representa um ganho, pois pelo menos se sabe de onde ela deriva. Além disso, como já havia sublinhado Freud (1911/1993a), com este deslocamento, a hostilidade do paranoico contra o objeto amado pode assim ser justificada: "o fato dele me controlar/perseguir me autoriza também a odiálo/criticá-lo". Sem contar que, com isso, o paranoico não faz senão denunciar a origem (externa) dos elementos de alteridade que o ameaçam (Tarelho, 1999b). O grande problema é que, longe de servir para controlar a angústia, esse deslocamento da ameaça para o outro, paradoxalmente, acaba simplesmente contribuindo para aguçá-la ainda mais, pois, além de reforçar a posição de exterioridade do superego, desperta a fera que habita imaginariamente dentro do outro, ainda mais que tudo isso, normalmente, produz uma reação contratransferencial negativa neste outro, o que só faz confirmar a suspeita e alimentar o circuito.

Não poderíamos encerrar essa discussão sem chamar a atenção para o sofrimento suplementar ao qual o paranoico se encontra submetido em função do papel que exerce seu superego no processo de percepção da realidade. Como vimos, em função, de um lado, da posição intermediária que ele ocupa (entre a tópica psíquica e a realidade externa) e, de outro, do nível de realidade ao qual pertencem os enclaves alojados em seu núcleo, ele favorece um deslocamento para a realidade material de elementos que acabam assumindo o mesmo status que essa última e produzindo um grau de convicção inabalável. Ora, essa convicção é submetida aos mais radicais desmentidos, o que coloca em xeque o tempo todo, no plano da representação, a sua capacidade perceptiva. Quem já se aventurou com este tipo de trabalho em análise conhece a dimensão do sofrimento que isso representa, pois esta é uma das questões centrais da relação transferencial com esse tipo de paciente. Um sofrimento que o analista sente na própria pele quando o paciente - e isso é inevitável - o coloca na parede e ele se vê interpelado sobre estas questões incontornáveis. Somos, assim, colocados diante das situações paradoxais às quais eles próprios são submetidos, tendo que se posicionar perante uma escolha impossível: curvar-se ao desmentido da realidade, que se esmera em conferir atestados de insanidade mental, tendo que negar a própria vivência subjetiva em que se inscreve o sofrimento, ou sustentar a qualquer custo as ideias delirantes, que permitem figurar o desejo e o sofrimento psíquico, tendo que enfrentar a negação dessa experiência pelo outro. Em ambos os casos, o sujeito se vê às voltas com a questão que se encontra inscrita em seu superego e que tem a ver com a negação de si próprio: de um lado, como sujeito de um saber sobre sua vivência perceptiva/subjetiva, e, de outro, como sujeito desejante. Como sair desse dilema, aparentemente insolúvel, e lidar com os sofrimentos subjacentes, são os maiores desafios que se colocam para esse tipo de análise.

\section{REFERÊNCIAS}

Anzieu, D. (1975). Le transfert paradoxal, de la communication paradoxale à la réaction thérapeutique négative. Nouvelle Revue de Psychanalyse, 12, 49-72.

Dayan, M. (1985). Les relations au réel dans la psychose. Paris: PUF.

Freud, S. (1969a). Manuscrito H. In: J. Strachey (Ed. e J. Salomão, Trad.), Edição Standard Brasileira das Obras Completas de Sigmund Freud. (Vol. I, pp. 253258). Rio de Janeiro: Imago. (Original publicado em 1895).

Freud, S. (1969b). Manuscrito K. In: J. Strachey (Ed. e J. Salomão, Trad.), Edição Standard Brasileira das Obras Completas de Sigmund Freud. (Vol. I, pp. 267276). Rio de Janeiro: Imago. (Original publicado em 1896).

Freud, S. (1969c). Observações adicionais sobre as psiconeuroses de defesa. In: J. Strachey (Ed. e J. Salomão, Trad.), Edição Standard Brasileira das Obras Completas de Sigmund Freud. (Vol. III, pp. 159-183). Rio de Janeiro: Imago. (Original publicado em 1896).

Freud, S. (1969d). Psicopatologia da vida cotidiana. In: J. Strachey (Ed. e J. Salomão, Trad.), Edição Standard Brasileira das Obras Completas de Sigmund Freud. (Vol. VI, pp. 13-311). Rio de Janeiro: Imago. (Original publicado em 1901).

Freud, S. (1969e). Delírios e sonhos na Gradiva de Jensen. In: J. Strachey (Ed. e J. Salomão, Trad.), Edição Standard Brasileira das Obras Completas de Sigmund Freud. (Vol. IX, pp. 15-93). Rio de Janeiro: Imago. (Original publicado em 1907).

Freud, S. (1969f). Sobre o narcisismo: uma introdução. In: J. Strachey (Ed. e J. Salomão, Trad.), Edição Standard Brasileira das Obras Completas de Sigmund Freud. (Vol. XIV, pp. 77-108). Rio de Janeiro: Imago. (Original publicado em 1914).

Freud, S. (1969g). Neurose e psicose. In: J. Strachey (Ed. e J. Salomão, Trad.), Edição Standard Brasileira das Obras Completas de Sigmund Freud. (Vol. XIX, pp. 165-176). Rio de Janeiro: Imago. (Original publicado em 1924).

Freud, S. (1989a). Más allá del principio de placer. In: J. L. Etcheverry (Trad.), Sigmund Freud Obras Completas. (Vol. XVIII, 1-62). Buenos Aires: Amorrortu Editores. (Original publicado em 1920).

Freud, S. (1989b). El problema económico del masoquismo. In: J. L. Etcheverry (Trad.), Sigmund Freud Obras Completas. (Vol. XIX, 161-176). Buenos Aires: Amorrortu Editores. (Original publicado em 1924). 
Freud, S. (1989c). Construcciones en el análisis. In: J. L. Etcheverry (Trad.), Sigmund Freud Obras Completas. (Vol. XXIII, 255-270). Buenos Aires: Amorrortu Editores. (Original publicado em 1937).

Freud, S. (1993a). Remarques psychanalytiques sur un cas de paranoïa (Dementia paranoides) décrit sous forme autobiographique. In: J. Laplanche (Ed. e A. Bourguignon e P. Cotet, Trad.), Sigmund Freud Oeuvres Complètes - Psychanalyse. (Vol. X, 225-304). Paris: PUF. (Original publicado em 1911).

Freud, S. (1993b). De quelques mécanismes névrotiques dans la jalousie, la paranoïa et l'homosexualité. In: J. Laplanche (Ed. e A. Bourguignon e P. Cotet, Trad.), Sigmund Freud Oeuvres Complètes - Psychanalyse. (Vol. XVI, 85-98). (Original publicado em 1921).

Lacan, J. (1966). Écrits. Paris: Seuil.

Laplanche, J. (1999). Séduction, persécution, révélation. In: J. Laplanche, Entre séduction et inspiration: l'homme (pp. 7-56). Paris: Presses Universitaires de France, coleção Quadrige.

MacGuirre, W. (1976). Freud/Jung - correspondência completa. Rio de Janeiro: Imago.
Racamier, P-C. (1991). Souffrir et survivre dans les paradoxes. Revue Française de Psychanalyse, 55, 893910.

Scarfone, D. (1994). Ma mère, ce n'est pas elle. De la séduction à la négation. In: J. André (Org.) Colloque international de psychanalyse Jean Laplanche (pp. 97106). Paris: PUF.

Tarelho, L. C. (1999a). Paranoïa et théorie de la séduction généralisée. Paris: PUF.

Tarelho, L. C. (1999b). Alteridade pulsional e projeção nas psicoses. Percurso, 23(2), 81-90.

Winnicott, D. W. (1975). O brincar e a realidade. Rio de Janeiro: Imago.

Endereço para correspondência: Luiz Carlos Tarelho. R. Marco Antonio Dias Batista, 35/93, Vila São Silvestre, CEP:05386320, São Paulo-SP, Brasil. E-mail: 1carlostarelho@gmail.com. 